\title{
Simple Device Design for Plume Management after Pneumoperitoneum in Laparoscopy in COVID-19 Outbreak
}

\author{
Gautam Ram Choudhary ${ }^{1} \cdot$ Deepak Kumar Ranjan ${ }^{2}$
}

Received: 17 May 2020 / Accepted: 14 June 2020 / Published online: 259June 2020

(C) Association of Surgeons of India 2020

\begin{abstract}
The impact of COVID-19 on surgical practice is worldwide. Controversy is there regarding dissemination of coronavirus by surgical smoke during laparoscopic surgery; hence, laparoscopic surgeries are being used with great cautions. We propose the use of a simple device, which can be prepared cheaply with material readily available in our hospitals, to manage the surgical plume generated during laparoscopic procedures. With proper management of the surgical plume with the above-proposed device, the concerns regarding aerosol generation can be alleviated and all the benefits of laparoscopy can be extended to our patient in need of a surgery that cannot be delayed.
\end{abstract}

Keywords Laparoscopy $\cdot$ Plume $\cdot$ Smoke $\cdot$ Cover- $19 \cdot$ Surgery

\section{Introduction}

In the era of coronavirus disease (COVID-19) pandemic, the use of minimally invasive surgery (laparoscopy, robotic-assisted laparoscopy, etc.) is considered controversial. Prime concern is pneumoperitoneum; surgical plume may have coronavirus and release of the same may put operation room personnel at risk of contracting COVID19. Minimally invasive surgery is key component of a surgeon's armamentarium by virtue of various proven benefits to patients and surgeons and it can be used with few precautions and modifications in current scenario.

\section{Concern}

The major concern pertaining specifically to minimally invasive surgery is aerosolization of viral particles via the

Gautam Ram Choudhary

gautamoshu@gmail.com; choudharygr@aiimsjodhpur.edu.in

Deepak Kumar Ranjan

depakranjan@gmail.com

1 Department of Urology, All India Institute of Medical Sciences, Jodhpur, Rajasthan 342005, India

2 Department of Urology and Renal Transplant, Yashoda Hospital, Secunderabad, Telangana, India pneumoperitoneum. To the best of our knowledge, there are no reports of the presence of severe acute respiratory syndrome coronavirus 2 (SARS-CoV-2) in the surgical plume generated during laparoscopic surgery as of yet. However, such risks can be extrapolated from previous studies on other viral infections. Literature supports presence of human papillomavirus (HPV), hepatitis B virus (HBV), and human immunodeficiency virus (HIV) in surgical smoke [1-3]. Although there is always a risk of viral transmission through surgical smoke, actual documented cases are rare [4].

\section{Simple resolution}

Irrespective of the rarity viral transmission via surgical plume, various measures have been proposed to deal with surgical smoke, i.e., use of smoke evacuation devices, low pneumoperitoneal pressure, minimizing setting of energy device, etc. We propose a simple device in dealing surgical plume to decrease live virus load if any. The picture shows a system in which a tube is connected to a laparoscopic port for controlled release of pneumoperitoneum into two successive sealed jars containing a sterilizing solution like 5.25-6.15\% sodium hypochlorite [https://www.cdc.gov/infectioncontrol/ guidelines/disinfection/disinfection-methods/chemical.html]. Routinely, laparoscopic procedure is performed at intraabdominal pressure between 8 and $12 \mathrm{~mm}$ of $\mathrm{Hg}$ [5]; hence, the tube connected for abdominal pressure may be merged in 


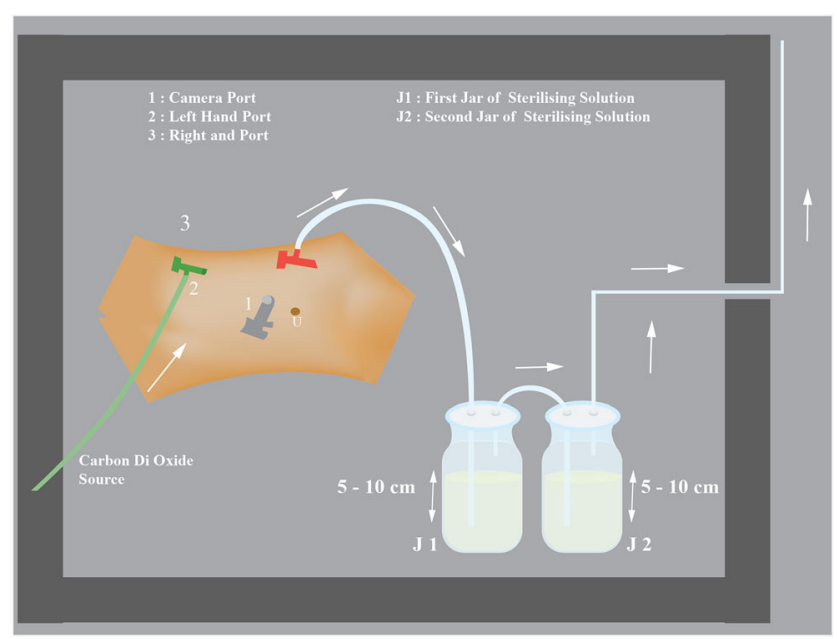

Fig. 1 Diagrammatic demonstration of safe laparoscopic smoke management in COVID 19 outbreak

sterilizing solution up to $8-10 \mathrm{~cm}$ of height [https://www. convertunits.com/from $/ \mathrm{mmHg} / \mathrm{to} / \mathrm{cmH} 2 \mathrm{O}]$. The jars must be at floor or at quite low level so at any point unwittingly it does not enter into the abdominal cavity. To overcome this issue, tubing with one-way valve can be used. Exit tube from second jar needs to have one-way valve and emerging gas can be collected in a biohazard container for safe disposal. The advantage of this device is that it can be easily assembled form readily available material in a standard hospital setting. In addition to that, it is quite cheap to make and with a proven virucidal activity of solution, it is a safe option. This device provides far superior containment and filtration of surgical smoke as compared with smoke generated during an open procedure. Minimal gas leak during exchange of laparoscopic hand instruments can be managed with sodium hypochloritesoaked gauge piece at trocar entry. Such a system in conjunction with general measures like tight port placement, keeping insufflation pressures at minimum, surgery in expert hands, and minimal use of energy devices at lowest possible settings, will definitely make laparoscopy safe and patient can avail all the benefits of a minimally invasive procedure [6, 7] (Fig. 1).

\section{Limitations}

We tried to propose a simple method of dealing the trail of smoke and pneumoperitoneum-related mixed aerosol on mere theoretical knowledge of authors. This has not applied for animal experimentation and ethical approval for clinical efficacy and, also, it has not been validated by a 3rd party.

\section{Future Scope}

Once laparoscopy surgeries resume after COVID19 outbreak and safety of laparoscopy in COVID19 patients considered safe with proper plume management, scientists may aim to know whether surgical plume has live coronavirus and if such device is effective, though we have not prepared any prototype for the same.

\section{Conclusion}

The possible risks for health professionals and the risks from operating on an asymptomatic patient positive for SARSCoV-2 are still unclear; however, certain measures should be taken to decrease risk. We believe, surgical plume management with abovementioned simple method can alleviate the risk of virus spread to healthcare workers in an operation room if any, safe and reproducible.

Acknowledgments The authors would like to thank the following: Dr. Rekha Choudhary, associate professor, Department of Obstetrics and Gynecology, Dr. S N Medical College, Jodhpur, for the contribution made in editing for resubmission; Dr. Himanshu Pandey, associate professor, Department of Urology, All India Institute of Medical Sciences, Jodhpur, for the contribution made in editing for resubmission; Mr. Himanshu Mishra, founder and CEO of PerfectPixel, for providing the image.

\section{Compliance with Ethical Standards}

Conflict of Interest The authors declare that they have no conflict of interest.

\section{References}

1. Hensman C, Baty D, Willis RG, Cuschieri A (1998) Chemical composition of smoke produced by high-frequency electrosurgery in a closed gaseous environment. An in vitro study. Surg Endosc 12(8): 1017-1019

2. Kwak HD, Kim S-H, Seo YS, Song K-J (2016) Detecting hepatitis B virus in surgical smoke emitted during laparoscopic surgery. Occup Environ Med 73(12):857-863

3. Alp E, Bijl D, Bleichrodt RP, Hansson B, Voss A (2006) Surgical smoke and infection control. J Hosp Infect 62(1):1-5

4. Liu Y, Song Y, Hu X et al (2019) Awareness of surgical smoke hazards and enhancement of surgical smoke prevention among the gynaecologists. J Cancer 10(12):2788-2799

5. Ishizaki Y, Bandai Y, Shimomura K, Abe H, Ohtomo Y, Idezuki Y (1993) Safe intraabdominal pressure of carbon dioxide pneumoperitoneum during laparoscopic surgery. Surgery. 114(3):549-554

6. Otto MA et al (2020) Rethink Urologic Cancer Treatment in the Era of COVID-19. Eur Urol. In press

7. Zheng MH, Boni L, Fingerhut A (2020) Minimally invasive surgery and the novel coronavirus outbreak: lessons learned in China and Italy. Ann Surg In Press

Publisher's Note Springer Nature remains neutral with regard to jurisdictional claims in published maps and institutional affiliations. 